\title{
Potential of Camellia sinensis proanthocyanidins-rich fraction for controlling malaria mosquito populations through disruption of larval development
}

\author{
Jackson M. Muema ${ }^{1 *}$, Joel L. Bargul ${ }^{1,2}$, Steven G. Nyanjom¹, James M. Mutunga ${ }^{3}$ and Sospeter N. Njeru ${ }^{4}$
}

\begin{abstract}
Background: Anopheles arabiensis and A. gambiae (sensu stricto) are the most prolific Afrotropical malaria vectors. Population control efforts of these two vectors have been hampered by extremely diverse larval breeding sites and widespread resistance to currently available insecticides. Control of mosquito larval stages using bioactive compounds of plant origin has the potential to suppress vector populations leading to concomitant reduction in disease transmission rates. In this study, we evaluated the efficacy of Camellia sinensis crude leaf extract and its fraction against the larvae of $A$. arabiensis and A. gambiae (s.s.).
\end{abstract}

Methods: Late third/early fourth instar larvae (L3/L4) of A. arabiensis and A. gambiae (s.s.) were exposed to increasing doses of $C$. sinensis leaf extract and its active fraction for $72 \mathrm{~h}$, with mortality rates recorded every $24 \mathrm{~h}$ in both control and test groups. Ultra performance liquid chromatography electron spray ionization quadruple time of flight coupled with mass spectrometry (UPLC/ESI-Qtof/MS) was used to determine the main active constituents in the fraction.

Results: The major bioactive chemical constituents in the C. sinensis leaf extract were identified to be proanthocyanidins. The extract significantly interfered with larval survival and adult emergence in both species (ANOVA, $F_{(5,24)}=1435.92$, $P<0.001$ ). Additionally, larval exposure to crude extract at $250 \mathrm{ppm}$ and $500 \mathrm{ppm}$ for $24 \mathrm{~h}$ resulted in larval mortality rates of over $90 \%$ in A. gambiae (s.s.) and $75 \%$ in A. arabiensis. A relatively lower concentration of $100 \mathrm{ppm}$ resulted in moderate mortality rates of $<50 \%$ in both species, but induced growth disruption effects evident as abnormal larval-pupal intermediates and disrupted adult emergence. The estimated $\mathrm{LC}_{50}$ concentrations of the crude leaf extract against A. arabiensis and A. gambiae (s.s.) larvae at $24 \mathrm{~h}$ were 154.58 ppm (95 \% Cl: 152.37-158.22) and 117.15 ppm (95\% Cl: 112.86-127.04), respectively. The bioactive polar fraction caused $100 \%$ larval mortality in both vector species at $25 \mathrm{ppm}$.

Conclusions: Our findings demonstrate the potential of green tea extract and its active constituents in disrupting mosquito larval development. This could contribute to the control of mosquito populations and improved management of malaria.

Keywords: Camellia sinensis, Proanthocyanidins, Anopheles gambiae (sensu stricto), Anopheles arabiensis, Larvicidal activity, Vector control

\footnotetext{
*Correspondence: Jackson_mbithi@yahoo.com

'Department of Biochemistry, Jomo Kenyatta University of Agriculture and

Technology, P.O. Box 62000-00200, Nairobi, Kenya

Full list of author information is available at the end of the article
}

\section{Ciomed Central}

(c) 2016 The Author(s). Open Access This article is distributed under the terms of the Creative Commons Attribution 4.0 International License (http://creativecommons.org/licenses/by/4.0/), which permits unrestricted use, distribution, and reproduction in any medium, provided you give appropriate credit to the original author(s) and the source, provide a link to the Creative Commons license, and indicate if changes were made. The Creative Commons Public Domain Dedication waiver (http://creativecommons.org/publicdomain/zero/1.0/) applies to the data made available in this article, unless otherwise stated. 


\section{Background}

Anopheles arabiensis and A. gambiae (s.s.) are the principal malaria vectors in Africa accounting for $88 \%$ of the newly-reported global malaria cases and $90 \%$ of the estimated death toll in 2015, impeding socio-economic growth in resource-constrained developing countries [1]. The diversity of mosquito breeding habitats hinders larval control efforts [2]. Currently, malaria vector control relies on integrated vector management (IVM) approaches such as targeting adult stages using long-lasting insecticide treated nets (LLINs) and indoor residual spraying (IRS), environmental management and larval source reduction $[1,3,4]$. Substantial reduction of mosquito populations has been achieved by targeting behavioral attributes of the adult mosquitoes and destruction of larval breeding sites [5]. However, evolution of insecticide resistance in mosquito vectors due to persistent application of chemical insecticides poses a great threat to elimination of malaria from endemic regions $[6,7]$. Virtually all the vector control strategies have limitations prompting the need for application of multiple control methods to reduce malaria transmission rates as well as offset insecticide resistance $[8,9]$. Thus, there is renewed interest in the search for novel chemicals that have reduced chances of development of resistance, especially ecofriendly natural compounds that are less toxic, or selectively toxic to mosquitoes [10].

Since ancient times, plants have been rich sources of effective natural insecticides [11]. For instance, Neem (Azadirachtica indica) derivatives are known to repel as well as inhibit growth in mosquitoes $[12,13]$. p-Menthane3,8-diol (PMD) from Eucalyptus plants elicit strong repellent effect against human biting mosquitoes [14]. Proanthocyanidins (condensed tannins) are among the allelochemicals produced by Camellia sinensis for defense against herbivory attacks [15]. These are oligomeric or polymeric products of auto-oxidation of flavan-3-ol catechins [16]. Proanthocyanidins are potent antioxidants possessing anti-cancer, anti-inflammatory, antibacterial, antiviral, nematicidal, anti-allergic, cardioprotective and cholesterol reducing activities [17, 18]. Ingestion of proanthocyanidins elicits deleterious effects on herbivory insects by attacking their midgut epithelia following breakdown into free radicals [19].

The immature mosquito stages breed in diverse habitats that may influence their vector competence [20, 21]. Biophysicochemical parameters of breeding habitats have effects on the larval productivity and vector population dynamics [22]. Perturbation of these habitat parameters with bioactive agents has been reported to significantly suppress mosquito populations [23] and can negatively impact vector competence and life history traits of resultant adult mosquitoes [24, 25]. Thus, targeting the immature stages of mosquitoes can be a viable approach towards elimination of malaria $[26,27]$.
Several studies have focused on the pharmacological potential of green tea phytochemicals particularly prevention and treatment of cancer, microbial infections, malaria, arthritis, cardiovascular diseases, inflammation, neurodegenerative diseases and other oxidative stress related diseases [28]. Currently, little is known about their potential role in control of medically important insect vectors. Our present study was motivated by previous reports that demonstrated the inhibitory effect of green tea extracts on larval development in Drosophila melanogaster, Aedes aegypti, Ae. albopictus and Culex quinquefasciatus [29, 30]. Further, green tea polyphenols have been shown to cause deleterious effects on the development and reproduction fitness of D. melanogaster [31]. Therefore, we designed a study to evaluate the efficacy of green tea leaf extract and its constituents against immature larval stages of $A$. arabiensis and A. gambiae (s.s.). Larvicidal and growth disruption effects of crude green tea leaf extract and its bioactive fraction against the mosquito immature stages were assessed. Our findings show that proanthocyanidins present in green tea extract reduced larval survival and adult emergence in both mosquito species by $100 \%$ at 25 ppm. A sublethal dose of 5 ppm induced growth disruption effects resulting in abnormal larval-pupal intermediates and abortive adult emergence.

\section{Methods \\ Experimental insects}

Late third and/or newly emerged fourth instar (L3/L4) larvae of $A$. arabiensis and A. gambiae (s.s.) were used for experimental studies. These larvae were obtained from a mosquito culture maintained at the International Centre of Insect Physiology and Ecology (icipe), Nairobi, Kenya. To establish an experimental larval colony, eggs oviposited on moist filter papers were placed into hatching trays containing $0.5 \mathrm{~L}$ dechlorinated water at $28 \pm 2{ }^{\circ} \mathrm{C}$. Following egg hatching, the mosquito larvae were kept in plastic trays $(39 \mathrm{~W} \times 28 \mathrm{~L} \times 14 \mathrm{D} \mathrm{cm})$ at densities of approximately 300 larvae per litre of distilled water and maintained under the following environmental conditions; $28 \pm 2{ }^{\circ} \mathrm{C}$ water temperature, $12 \mathrm{~L}: 12 \mathrm{D}$ photoperiod and 55-60\% relative humidity. Larvae were fed with $0.3 \mathrm{mg}$ Tetramin ${ }^{\circledR}$ fish meal (Tetra GmbH, Melle, Germany) once every 3 days.

\section{Collection of plant material and extraction}

Fresh immature leaves of green tea, $C$. sinensis (clone TRFK 6/8), were collected from Limuru Archdiocesan Farm (Limuru, Kenya; GPS coordinates: 01 $07^{\prime} 10^{\prime \prime} \mathrm{S}, 036^{\circ}$ 39'37"E; 2,225 m above sea level) in February 2016 with permission to use the plant for this study from Archdiocesan farmers. The tea leaves were shade-dried at $25 \pm 2{ }^{\circ} \mathrm{C}$ with intermittent aeration to a constant weight. Air-dried 
tea leaves were milled into powder using an electric grinder (Model 5657; Retsch GmbH, Haan, Germany). Five hundred grams $(500 \mathrm{~g})$ of the pulverized leaf powder was infused in $2 \mathrm{~L}$ of $90 \%$ methanol for $72 \mathrm{~h}$ with intermittent shaking. The extract was filtered with Whatman 1 filter paper (Whatman Inc., Haverhill, USA) and excess solvent removed via rotor evaporation. The residual extract was lyophilized in a freeze dryer (Labconco stoppering tray dryer, Labconco Corporation, USA) programmed at $13{ }^{\circ} \mathrm{C}$ temperature, vacuum pressure of $998 \times 10^{-3}$ millibars and collector at $-40{ }^{\circ} \mathrm{C}$. The resultant extract was stored at $-20^{\circ} \mathrm{C}$ until use.

\section{Fractionation of crude green tea extract}

Fractionation of active constituents in the crude leaf extract was performed on silica-packed column chromatography. Silica (200 g; Kiesegel 60 M [0.004-0.063 mm mesh size]; Macherey-Nagel GmbH \& Co.KG, Düren, Germany) was packed in $40 \times 330 \mathrm{~mm}$ column and conditioned with analytical grade n-hexane (Sigma Aldrich, St. Louis, USA) for $3 \mathrm{~h}$ prior sample loading. Thirty-five grams of the leaf extract were loaded onto the packed silica and elution of various fractions achieved through gradient mobile phase of analytical grade $\mathrm{n}$-hexane and ethyl acetate (100:0-0:100) and finally methanol (Sigma Aldrich, St. Louis, USA). Fractions were chromatographed on thin layer chromatography (TLC) silica plates (ALUGRAM ${ }^{\circ}$ Xtra SIL G/UV 254 [0.2 mm], Macherey-Nagel GmbH \& Co.KG, Düren, Germany) developed with n-hexane and ethyl acetate $(1: 2 v / v)$ as mobile phase. The plates were air-dried, sprayed with $30 \%$ sulfuric acid and baked in an oven for detection under UV lamp $\left(\lambda_{254-365} \mathrm{~nm}\right)$. Based on TLC monitoring and evaluations, fractions with similar retention factor ( $\mathrm{Rf}$ ) values were pooled together, rotor-evaporated and assayed for activity against mosquito larvae.

\section{Larvicidal activity of green tea extract}

Larvicidal assays were conducted following the World Health Organization (WHO) guidelines [32]. Batches of twenty (20) L3/L4 instar mosquitoes were placed in $250 \mathrm{ml}$ glass beakers containing $100 \mathrm{ml}$ of different concentrations of leaf extract (i.e. 500 ppm, 250 ppm, 100 ppm, 50 ppm and $25 \mathrm{ppm})$ and its fraction $(25 \mathrm{ppm}, 10 \mathrm{ppm}, 5 \mathrm{ppm}$, $2.5 \mathrm{ppm}$ and $1 \mathrm{ppm})$. Five replicates were set for each treatment dose $(n=100$ larvae) and an untreated control $(n=100$ larvae) was included in each experiment. The doses were formulated by separately dissolving $250 \mathrm{mg}$, $125 \mathrm{mg}, 50 \mathrm{mg}, 25 \mathrm{mg}$ and $12.5 \mathrm{mg}$ of leaf extract and $12.5 \mathrm{mg}, 5 \mathrm{mg}, 2.5 \mathrm{mg}, 1.25 \mathrm{mg}$ and $0.5 \mathrm{mg}$ of active fraction in $1 \mathrm{ml}$ of reagent grade absolute ethanol (Fisher Scientific, Loughborough, UK) and diluting into respective doses with $499 \mathrm{ml}$ distilled water. The negative control experiment was set up by placing larvae in $0.2 \%$ of ethanol diluted in distilled water.

\section{Quantification of larval mortality rates}

Equal starting numbers of larvae $(n=20$ larvae) were placed into each beaker containing different concentrations of leaf extract and active fractions. Mortality rates of treated larvae were quantified at $24 \mathrm{~h}$ intervals. Each larva was examined and considered dead if it did not respond to probing with a dropper. Morphological defects of larvae induced by treatment with tea leaf extract relative to controls were analyzed using light microscopy at $25 \times$ magnification (Leica Corporation, Heerbrugg, Switzerland). High resolution images of larvae were captured and recorded for further analysis.

\section{UPLC/ESI-Qtof/MS analysis}

In order to re-dissolve the bioactive fraction, $1.5 \mathrm{mg}$ was mixed with $1 \mathrm{ml}$ of LC-MS grade CHROMASOLV methanol (Sigma-Aldrich, St. Louis, USA) and centrifuged at $14000 \times \mathrm{rpm}$ for $5 \mathrm{~min}$, after which $0.2 \mu \mathrm{l}$ of the supernatant was automatically injected into UPLC/ESI-Qtof/ MS. The chromatographic separation was achieved on a Waters ACQUITY UPLC (ultra-performance liquid chromatography) I-class system (Waters Corporation, Milford, USA) fitted with a $2.1 \mathrm{~mm} \times 50 \mathrm{~mm}, 1.7 \mu \mathrm{m}$ particle size Waters ACQUITY UPLC BEH C18 column (Waters Corporation, Dublin, Ireland) heated to $40{ }^{\circ} \mathrm{C}$ and autosampler tray cooled to $5{ }^{\circ} \mathrm{C}$. Mobile phases of water (A) and acetonitrile (B) each containing $0.01 \%$ formic acid were employed. The following gradient was used: $0-5 \mathrm{~min}$, $10 \% \mathrm{~B} ; 5-7 \mathrm{~min}, 10-60 \% \mathrm{~B} ; 7-10 \mathrm{~min}, 60-80 \% \mathrm{~B}$; 10-15 min, $80 \% \mathrm{~B} ; 15-18 \mathrm{~min}, 100 \% \mathrm{~B} ; 18-20 \mathrm{~min}$, $100 \%$ B; $20-21.5$ min $100-10 \%$ B; $21.5-25 \min 10 \%$ B. The flow rate was held constant at $0.4 \mathrm{ml} \mathrm{min}^{-1}$. The UPLC system was interfaced with electrospray ionization (ESI) to a Waters Xevo Qtof-MS operated in full scan $\mathrm{MS}^{\mathrm{E}}$ in positive mode. Data were acquired in resolution mode over the $\mathrm{m} / \mathrm{z}$ range $100-1,200$ with a scan time of $1 \mathrm{~s}$ using a capillary voltage of $0.5 \mathrm{kV}$, sampling cone voltage of $40 \mathrm{~V}$, source temperature $100{ }^{\circ} \mathrm{C}$ and desolvation temperature of $350^{\circ} \mathrm{C}$. The nitrogen desolvation flow rate was $500 \mathrm{l} / \mathrm{h}$. For the high-energy scan function, a collision energy ramp of $25-45 \mathrm{eV}$ was applied in the $\mathrm{T}$-wave collision cell using ultrahigh purity argon $(\geq 99.999 \%)$ as the collision gas. A continuous lock spray reference compound (leucine enkephalin; $[\mathrm{M}+\mathrm{H}]^{+}=556.2766$ ) was sampled at $10 \mathrm{~s}$ intervals for centroid data mass correction. The mass spectrometer was calibrated across the $50-1,200$ Da mass range using a $0.5 \mathrm{mM}$ sodium formate solution prepared in 90:10 2-propanol/water $(v / v)$. Mass Lynx version 4.1 SCN 712 (Waters Corporation, Milford, USA) was used for data acquisition and processing. The elemental composition was generated for every analyte. 
Potential assignments were calculated using mono-isotopic masses with a tolerance of $10 \mathrm{ppm}$ deviation and both odd- and even-electron states possible. The number and types of expected atoms was set as follows: carbon $\leq 100$; hydrogen $\leq 100$; oxygen $\leq 50$; nitrogen $\leq 6$; sulfur $\leq 6$. The UPLC/ESI-Qtof/MS data acquisition and analysis were based on the following parameters: mass accuracy $(\mathrm{ppm})=1,000,000 \times($ calculated mass-accurate mass)/calculated mass; fit conf $\%$ is the confidence with which the measured mass (accurate mass) matches the theoretical isotope models of the elemental composition in the list; elemental composition is a suggested formula for the specified mass. This reflects a summation of the quantities of elements, isotopes or superatoms that can comprise the measured data, calculated using the following atomic masses of the most abundant isotope of the elements: $\mathrm{C}=12.0000000, \mathrm{H}=1.0078250, N=14.0030740$, $\mathrm{O}=15.9949146, \mathrm{~S}=31.9720718$. The empirical formulae generated were used to predict structures and proposed based on the online databases (Chemspider, Metlin) and published literature $[33,34]$.

\section{Data analysis}

Data were entered and organized in Microsoft Excel 2010 spreadsheet then exported to R software version 3.2.3 (The R Project for Statistical Computing, www.r-project.org) for analyses. Corrected mortality rates were expressed as \% mean \pm standard deviation (SD) for each tested dose. The test concentrations were $\log _{10}$-transformed to reduce variation prior to fitting a dose-response model for estimating lethal dose concentrations. Nonlinear regression using $\mathrm{glm}$ function in $\mathrm{R}$ with probit link and quasi binomial distribution error was used to estimate the lethal concentrations of crude extract and its active fraction. $\mathrm{LC}_{50}$ of both the crude extract and its active fraction were estimated from the $\mathrm{glm}$ output using the dose.p function in MASS Package in R. The significance of differences between treatment means was determined by analysis of variance (ANOVA) with values of $P<0.05$ considered statistically significant. Graphs were designed using GraphPad Prism version 7.0 for Windows (GraphPad Software, San Diego, USA). Images were processed using publicly-available IMAGEJ software (National Institutes of Health, https://imagej.nih.gov/ij/).

\section{Results \\ Phytochemistry}

Phytochemical analysis of the bioactive methanolic fraction detected 6 major biologically-active compounds, in addition to a protein and 3 unknown compounds (Table 1 ). Proanthocyanidins $\left(\mathrm{C}_{31} \mathrm{H}_{28} \mathrm{O}_{12}\right) \mathrm{m} / z[\mathrm{M} / \mathrm{H}]^{+} 593.2830$ (15.2641 \%) were detected through UPLC/ESI-Qtof/MS as the most abundant compounds in the bioactive fraction of tea extract (Fig. 1). Other prominent mass spectrum peaks that denote bioactive compounds were $\mathrm{m} / \mathrm{z} 195.0919$ $\left(\mathrm{C}_{8} \mathrm{H}_{11} \mathrm{~N}_{4} \mathrm{O}_{2}\right) \quad$ (2), $303.0516 \quad\left(\mathrm{C}_{15} \mathrm{H}_{10} \mathrm{O}_{7}\right) \quad(3), \quad 287.0566$ $\left(\mathrm{C}_{15} \mathrm{H}_{10} \mathrm{O}_{6}\right)$ (4), $903.2551\left(\mathrm{C}_{42} \mathrm{H}_{46} \mathrm{O}_{22}\right)$ (5) and 887.2620 $\left(\mathrm{C}_{42} \mathrm{H}_{46} \mathrm{O}_{21}\right)$ (6). A database search tentatively identified the compounds represented by peak $2\left(R_{t} 3.06 \mathrm{~min}\right)$ as Caffeine, peak $3\left(R_{t} 4.42 \mathrm{~min}\right)$ Quercetin, peak $4\left(\mathrm{R}_{\mathrm{t}}\right.$ $5.10 \mathrm{~min})$ Kaempferol, peak $5\left(\mathrm{R}_{\mathrm{t}} 8.56 \mathrm{~min}\right)$ Kaempferol rhamnoside and peak $6\left(R_{t} 8.56\right.$ min) Kaempferol rhamnosyl glucoside (Table 1 and Fig. 1).

\section{Toxicity effects of leaf extract and its fraction on mosquito larvae}

Larval survival and adult emergence was significantly reduced when L3/L4 instars of $A$. arabiensis and A. gambiae (s.s.) were exposed to different concentrations of crude extract and its bioactive fraction (ANOVA, $F_{(5,24)}=1435.92$, $P<0.001)$. The untreated control group achieved $100 \%$ survival rates for the entire analysis period. Higher extract

Table 1 Tentative identification of the constituents of $C$. sinensis bioactive fraction. Data show tentative identification of compounds within the bioactive fraction of $C$. sinensis extract from published literature and publicly accessible online databases, monoisotopic

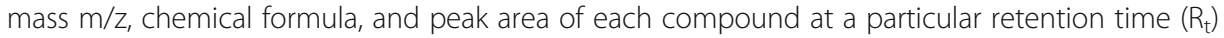

\begin{tabular}{lcccll}
\hline No. & $\mathrm{R}_{\mathrm{t}}(\mathrm{min})$ & $\mathrm{m} / \mathrm{z}[\mathrm{M}+\mathrm{H}]^{+}$ & Peak area $(\%)$ & Chemical formula & \multicolumn{1}{l}{ Tentative identification } \\
\hline 1 & 0.84 & 158.0822 & 2.1269 & $-^{a}$ & Unknown $^{\mathrm{b}}$ \\
2 & 3.06 & 195.0919 & 7.0454 & $\mathrm{C}_{8} \mathrm{H}_{11} \mathrm{~N}_{4} \mathrm{O}_{2}$ & Caffeine \\
3 & 4.42 & 303.0516 & 4.9190 & $\mathrm{C}_{15} \mathrm{H}_{10} \mathrm{O}_{7}$ & Quercetin \\
4 & 5.10 & 287.0566 & 6.0235 & $\mathrm{C}_{15} \mathrm{H}_{10} \mathrm{O}_{6}$ & Kaempferol \\
5 & 8.52 & 903.2551 & 1.4543 & $\mathrm{C}_{42} \mathrm{H}_{46} \mathrm{O}_{22}$ & Kaempferol rhamnoside \\
6 & 8.56 & 887.2620 & 0.6415 & $\mathrm{C}_{42} \mathrm{H}_{46} \mathrm{O}_{21}$ & Kaempferol rhamnosyl glucoside \\
7 & 16.00 & 621.2712 & 6.3769 & - & Unknown \\
8 & 16.15 & 593.2830 & 15.2641 & $\mathrm{C}_{31} \mathrm{H}_{28} \mathrm{O}_{12}$ & Proanthocyanidin \\
9 & 16.52 & 607.2932 & 9.4702 & $\mathrm{C}_{36} \mathrm{H}_{38} \mathrm{~N}_{4} \mathrm{O}_{5}$ & Phenyl peptide \\
10 & 21.44 & 954.6154 & 2.3624 & - & Unknown \\
\hline
\end{tabular}

a-Represents missing chemical formula for the compounds with serial number 1, 7 and 10

b'Unknown' means that compound was unidentifiable from searched databases and published literature 


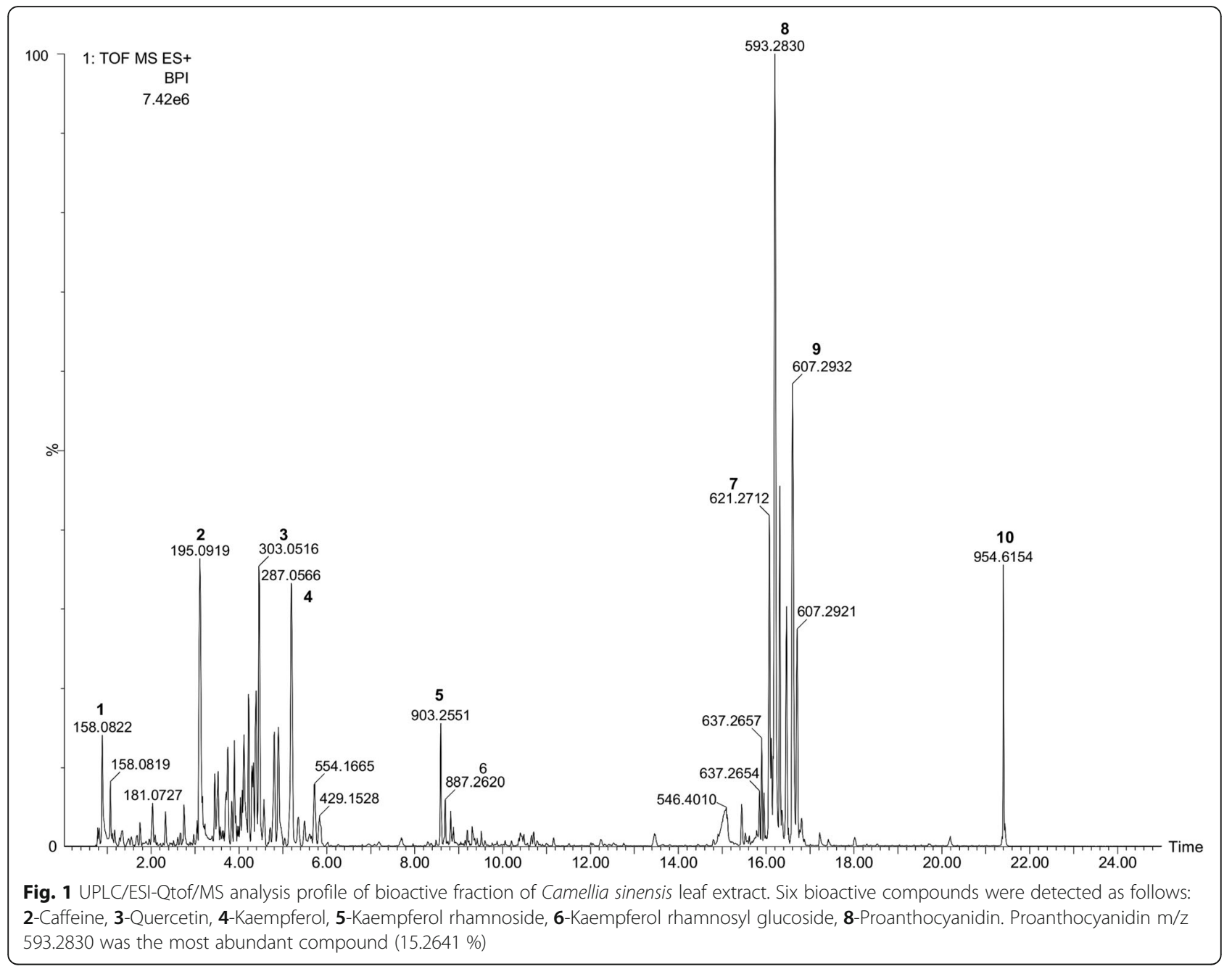

doses (250 ppm and $500 \mathrm{ppm}$ ) evoked more than $90 \%$ larval mortality in A. gambiae (s.s.) and $75 \%$ in A. arabiensis at $24 \mathrm{~h}$ post-exposure (Table 2). At $24 \mathrm{~h}$ postexposure, the estimated $\mathrm{LC}_{50}$ dose and its associated $95 \%$ confidence intervals for $A$. arabiensis was $154.58 \mathrm{ppm}$ (152.37-158.22), and for A. gambiae (s.s.) was $117.15 \mathrm{ppm}$ (112.86-127.04). Our results indicate that, larval survival rates significantly reduced with prolonged exposure $(72 \mathrm{~h})$ relative to controls (ANOVA, $F_{(5,24)}=117.64, P<0.001$; Table 2). A sublethal dose of extract at $100 \mathrm{ppm}$ induced growth disruption effects characterized by: failure of larvae to molt into pupae, resulting into abnormal larval-pupal intermediates (Fig. 3c, d) and death of adults during eclosion from the pupal stage, with their legs and wings stuck in pupal caste (Fig. 3e, f).

Further, we investigated the larvicidal efficacy of the bioactive fraction by exposing the larvae to $25 \mathrm{ppm}, 10 \mathrm{ppm}$, $5 \mathrm{ppm}, 2.5 \mathrm{ppm}$ and $1 \mathrm{ppm}$. Maximum larval mortality rates of $100 \%$ were attained at $25 \mathrm{ppm}$ treatment dose within $24 \mathrm{~h}$ incubation in both $A$. arabiensis and A. gambiae (s.s.) (Table 3 and Fig. 2). Moderate larval toxicity that increased with incubation duration reaching peak levels at $72 \mathrm{~h}$ post-exposure occurred at 2.5, 5 and $10 \mathrm{ppm}$, whereas minimal toxicity was recorded at $1 \mathrm{ppm}$ exposure. Growth disruption effects similar to those induced by the crude extract at $100 \mathrm{ppm}$ were observed at $5 \mathrm{ppm}$ (Fig. 3). Differences between the treatment means were not statistically significant (ANOVA, $\left.F_{(5,24)}=85.33, P<0.001\right)$.

Treatment of mosquito larvae with sublethal doses of green tea bioactive fraction exerted growth disruption effects after $72 \mathrm{~h}$ of exposure (Fig. 3). Progression of metamorphosis, from larva to pupa and finally adult, was halted resulting into abnormal larval-pupal intermediates and arrested adult emergence. Further, some adults that successfully emerged from the larvicide treated water were unable to fly from the test beakers and died on the water surface, a phenomenon similarly observed with crude extract at $100 \mathrm{ppm}$.

\section{Discussion}

Malaria-transmitting mosquitoes have developed physiological and behavioral mechanisms to successfully evade 
Table 2 Acute toxicity of crude green tea (Camellia sinensis) extract on exposure to L3/L4 instars of A. arabiensis and A. gambiae (s.s.) for 24, 48 and $72 \mathrm{~h}$ post-exposure. Summary of percentage mean ( \pm SD) mortality rates of five replicates of mosquito larvae exposed to different concentrations of $C$. sinensis crude leaf extract for different time periods ( 24,48 and 72 h). Half maximal lethal concentrations $\left(L_{50}\right)$ for each dose exposure period have been determined at their $95 \%$ confidence intervals. The mosquito larvae exhibited significant susceptibility to the bioactive fraction at $P<0.05$

\begin{tabular}{|c|c|c|c|c|c|c|c|c|}
\hline \multirow[b]{2}{*}{ Time } & \multicolumn{6}{|c|}{ Concentration (ppm) } & \multicolumn{2}{|c|}{ Lethal concentration (ppm) } \\
\hline & 500 & 250 & 100 & 50 & 25 & Control & $\mathrm{LC}_{50}$ & $95 \% \mathrm{Cl}$ \\
\hline \multicolumn{9}{|c|}{ An. arabiensis* } \\
\hline $24 \mathrm{~h}$ & $86 \pm 9.62$ & $75 \pm 24.75$ & $30 \pm 19.69$ & $0 \pm 0.00$ & $0 \pm 0.00$ & $0 \pm 0.00$ & 154.58 & 152.37-158.22 \\
\hline $48 \mathrm{~h}$ & $98 \pm 4.47$ & $92 \pm 5.70$ & $53 \pm 20.19$ & $0 \pm 0.00$ & $0 \pm 0.00$ & $0 \pm 0.00$ & 154.58 & 152.37-158.22 \\
\hline $72 \mathrm{~h}$ & $100 \pm 0.00$ & $95 \pm 5.00$ & $60 \pm 18.03$ & $0 \pm 0.00$ & $0 \pm 0.00$ & $0 \pm 0.00$ & 154.58 & 152.37-158.22 \\
\hline \multicolumn{9}{|c|}{ An. gambiae (s.s.) ${ }^{*}$} \\
\hline $24 \mathrm{~h}$ & $100 \pm 0.00$ & $91 \pm 9.62$ & $39 \pm 6.52$ & $0 \pm 0.00$ & $0 \pm 0.00$ & $0 \pm 0.00$ & 117.15 & $112.86-127.04$ \\
\hline $48 \mathrm{~h}$ & $100 \pm 0.00$ & $98 \pm 2.24$ & $62 \pm 10.37$ & $0 \pm 0.00$ & $0 \pm 0.00$ & $0 \pm 0.00$ & 87.11 & $82.57-112.82$ \\
\hline $72 \mathrm{~h}$ & $100 \pm 0.00$ & $100 \pm 0.00$ & $84 \pm 11.94$ & $0 \pm 0.00$ & $0 \pm 0.00$ & $0 \pm 0.00$ & 87.11 & $82.57-112.82$ \\
\hline
\end{tabular}

Data presented as mean \pm SD of five replicates

Abbreviations: $L C_{50}$ lethal concentration that killed $50 \%$ of test mosquito larvae population, $C l$ confidence interval

*Mean values are not significantly different $P \leq 0.05$ (ANOVA)

population control strategies targeting adult stages [7]. Limitations imposed by these vector control tools have necessitated complementary strategies. Larviciding, a lesspracticed component of integrated vector management, has traceable history of success in eradication of malaria from Brazil and Egypt and currently revived in some African countries [26, 35]. Mosquito metamorphosis represents a low cost and feasible target of population regulation through interfering with development of immature stages [36]. Despite the dramatic reduction in mosquito populations on persistent application of chemical insecticides, negative implications have limited their continued use [37]. Thus, development of safe, novel and selectively toxic larvicides has been welcomed into integrated mosquito control programmes [38, 39]. Principally, their anticipated multimodal actions against target arthropods limit chances of resistance development and could be a pathway to designing resistant-resilient insecticides [40]. Prospection for use of plant-derived insect growth regulators as biolarvicides has gained considerable attention aimed at disrupting successful development of agricultural and medical nuisance insects including mosquitoes [10, 13, 41].

In this study, we aimed to evaluate whether green tea could be a potential source of mosquito control agents, by investigating its efficacy against larvae of A. gambiae (s.s.) and $A$. arabiensis. We found that, the initial larval bioassays with crude leaf extract significantly reduced survival and development of larval stages in both mosquito species

Table 3 Acute toxicity in L3/L4 instars of A. arabiensis and A. gambiae (s.s.) resulting from treatment of larvae with the active green tea fraction for 24,48 and 72 h. Data presented below indicates the percentage means ( \pm S.D) of mortality rates of mosquito larvae exposed to different concentrations of bioactive fraction of $C$. sinensis extract for different time periods (24, 48 and 72 h). Five replicates were included in the study. Half maximal lethal concentrations $\left(\mathrm{LC}_{50}\right)$ for each dose exposure period have been determined at their $95 \%$ confidence intervals. The mosquito larvae exhibited significant susceptibility to the bioactive fraction at $P<0.05$

\begin{tabular}{|c|c|c|c|c|c|c|c|c|}
\hline \multirow[b]{2}{*}{ Time } & \multicolumn{6}{|c|}{ Concentration (ppm) } & \multicolumn{2}{|c|}{ Lethal concentration (ppm) } \\
\hline & 25 & 10 & 5 & 2.5 & 1 & Control & $\overline{L C_{50}}$ & $95 \% \mathrm{Cl}$ \\
\hline \multicolumn{9}{|c|}{ An. arabiensis* } \\
\hline $24 \mathrm{~h}$ & $100 \pm 0.00$ & $62 \pm 10.37$ & $20 \pm 6.12$ & $13 \pm 9.08$ & $0 \pm 0.00$ & $0 \pm 0.00$ & 7.37 & $3.98-12.64$ \\
\hline $48 \mathrm{~h}$ & $100 \pm 0.00$ & $69 \pm 9.62$ & $33 \pm 9.08$ & $17 \pm 10.37$ & $0 \pm 0.00$ & $0 \pm 0.00$ & 6.22 & $3.04-11.06$ \\
\hline $72 \mathrm{~h}$ & $100 \pm 0.00$ & $76 \pm 9.62$ & $43 \pm 9.08$ & $25 \pm 10.00$ & $0 \pm 0.00$ & $0 \pm 0.00$ & 5.20 & $2.17-9.70$ \\
\hline \multicolumn{9}{|c|}{ An. gambiae (s.s.)* } \\
\hline $24 \mathrm{~h}$ & $100 \pm 0.00$ & $69 \pm 17.10$ & $42 \pm 8.37$ & $25 \pm 14.58$ & $0 \pm 0.00$ & $0 \pm 0.00$ & 5.52 & $2.68-9.65$ \\
\hline $48 \mathrm{~h}$ & $100 \pm 0.00$ & $78 \pm 2.24$ & $56 \pm 12.94$ & $32 \pm 14.40$ & $0 \pm 0.00$ & $0 \pm 0.00$ & 4.45 & $1.55-8.71$ \\
\hline $72 \mathrm{~h}$ & $100 \pm 0.00$ & $88 \pm 9.08$ & $70 \pm 11.18$ & $38 \pm 14.40$ & $0 \pm 0.00$ & $0 \pm 0.00$ & 3.60 & $0.29-8.71$ \\
\hline
\end{tabular}

Data presented as mean \pm SD of five replicates

Abbreviations: $L C_{50}$ lethal concentration that killed $50 \%$ of test mosquito larvae population, $C l$ confidence interval

* Mean values are not significantly different $P \leq 0.05$ (ANOVA) 


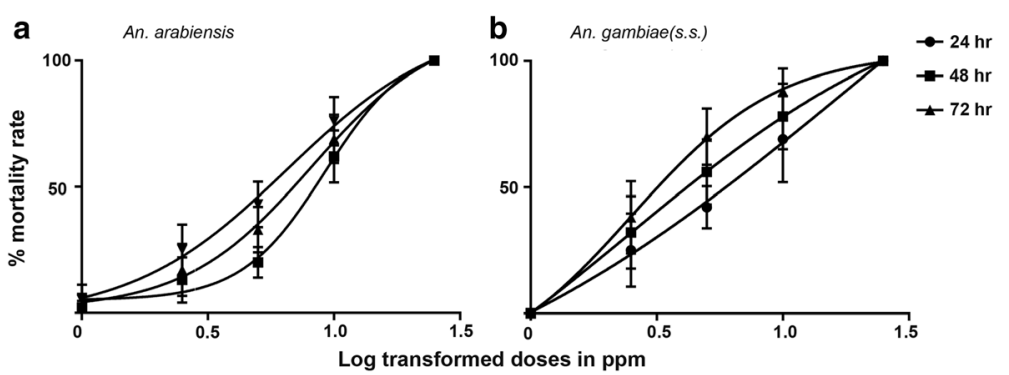

Fig. 2 Dose-response curves showing treatment effects of bioactive fraction of C. sinensis on A. arabiensis and A. gambiae (s.s.) larvae at 24,48 and $72 \mathrm{~h}$ post-exposure. Doses of the extract are log-transformed. The curves show dose-response fitted models of $A$. arabiensis (a) and A. gambiae (s.s.) (b) larvae, treated with bioactive fraction of $C$. sinensis at different exposure time periods (24, 48 and $72 \mathrm{~h}$ ). Each point on the curve represents percentage mean ( \pm standard deviation, SD) larval mortality of five replicates for a particular dose

suggesting presence of biologically active phytochemicals. This necessitated fractionation in order to isolate specific bioactive ingredients, tentatively identified as caffeine, quercetin, kaempferol, kaempferol rhamnoside, kaempferol rhamnosyl glucoside and proanthocyanidins.

Consistent with previous results from studies conducted on other insects [29-31], C. sinensis extract exhibited larvicidal activity in addition to induction of growth disruption effects. However, in contrast to our dosage data, these studies reported relatively higher extract dosages of between $10 \mathrm{mg} / \mathrm{ml}$ to $75 \mathrm{mg} / \mathrm{ml}$ (translating to $10,000-75,000 \mathrm{ppm}$ ) to achieve similar larvicidal potency. The varied observations could be attributed to susceptibility difference of test insects, variation in abundance of bioactive constituents in plant extracts, extraction method and geographical location of the studied plants. Contrary to these studies which attributed toxicity effects to polyphenolic constituents of
C. sinensis especially the abundant (-)-epigallocatechin-3gallate (EGCG) [31], we found proanthocyanidins to be the abundant bioactive compounds most strongly associated with the observed effects. Surprisingly, catechins were not detected in the bioactive fraction. However, proanthocyanidins are polyphenolic products of catechins epimerization associated with plant defenses [16, 19]. The other compounds identified within the fraction might have contributed towards exerting synergistic or racemic mixture effects to proanthocyanidins.

Caffeine has been reported to interfere with mosquito larval development [42]. The hydroxylflavones, quercetin and kaempferol, induce cell cycle arrest by inhibiting CDC25A tyrosine phosphate at G2/M phase and/or inducing apoptosis [43]. In nature, polyphenolic compounds including proanthocyanidins (condensed tannins) and other flavonoids form part of defense against fungal

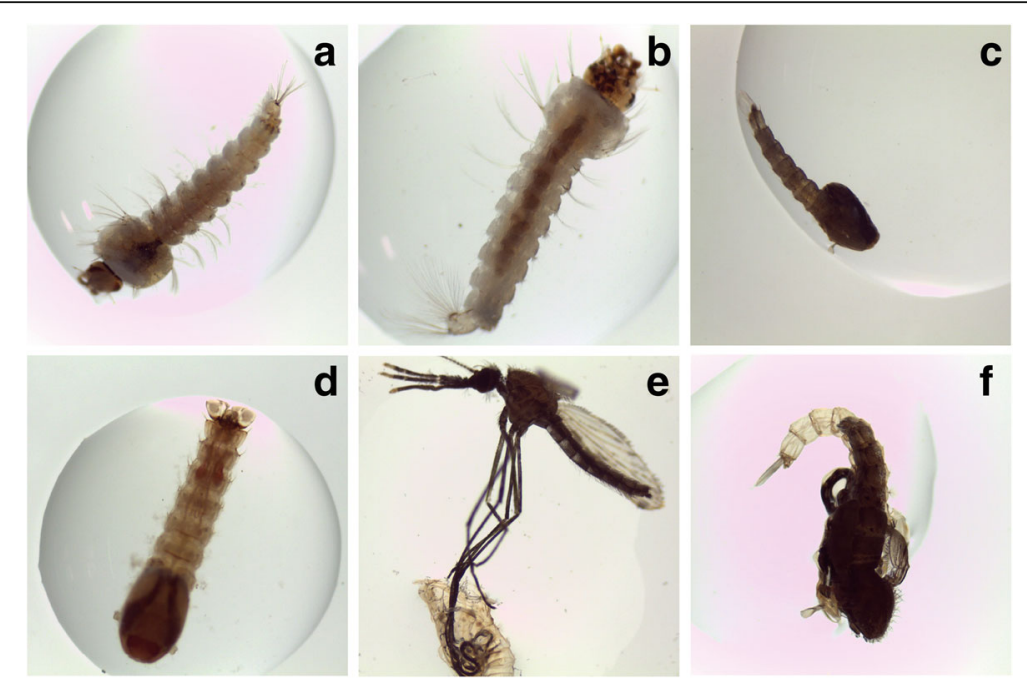

Fig. 3 Growth disruption effects mediated by Camellia sinensis extract at $72 \mathrm{~h}$ post-exposure. a Anopheles gambiae (s.s.) control larva. b Anopheles arabiensis control larva. c Abnormal A. gambiae (s.s.) larval-pupal intermediate. d Abnormal An. arabiensis larval-pupal intermediate. e Aborted adult emergence in A. gambiae (s.s.) with legs stuck in pupal caste. $\mathbf{f}$ An. arabiensis adult emergence arrested (visualization of the changes in larval morphology before and after treatment with extract was monitored using light microscopy at $25 \times$ magnification) 
attacks and insect herbivory in plants [44]. They provoke feeding deterrence with intense disorganization of midgut epithelia cells upon ingestion, which concomitantly reduces insect survival and development [45]. The fact that green tea polyphenolic compounds exert anti-carcinogenic effect by inducing cell cycle arrest, apoptosis and growth inhibition could also be implicated in this study $[46,47]$. The post-embryonic stages of insects comprise of cell proliferation and DNA replication events preceding growth and morphogenetic organization [48]. As proanthocyanidins are pro-oxidants and pro-apoptotic molecules that astringently precipitate cellular proteins [49], they could presumably halt these events in developing insects resulting to death. Also, the compounds bind to nucleic acids, increasing topoisomerase II DNA cleavage activity, inducing DNA breaks and reduced cell survival [50, 51]. Taken together, these mechanisms could be attributable to the impaired larval development and toxicity.

Although molecular studies were not included in this study to determine the linkage between the genotype and the observed morphological traits, peculiar observations were noted in regard to developmental phenotypes. Incubation of the mosquito larvae with sublethal dose of $5 \mathrm{ppm}$ of the bioactive fraction induced developmental defects (Fig. 3) similar to those exhibited by insect growth regulators (IGRs) [52, 53]. The transition of mosquito larvae into adult stage was found to fail at larval-pupal intermediates, while others remained permanently stuck as they eclosed. Insect growth regulatory (IGR) compounds act by adversely interfering with physiologically and hormonally-regulated developmental events resulting into immature deaths and non-viable reproductive adults $[52,54]$. Commonly known IGRs are insect developmental hormone agonists that mimic the actions of juvenile hormone and ecdysone while others inhibit chitin synthesis [55, 56]. Interestingly, among the compounds tentatively identified in the bioactive fraction, none seemed structurally similar to insect developmental hormones, ecdysteroid 20-hydroxyecdysone (20-E) and sesquiterpenoid juvenile hormone $(\mathrm{JH})$. However, the presence of flavonoid-like polyphenols in the larval breeding water suggested modulated neuroendrocrine signaling networks interfering with larval development [57]. Of importance is insulin/insulin-like pathway, a conserved regulatory signaling pathway that coordinate insect growth and metamorphosis by regulating biosynthesis of development hormones [58-60]. Other studies have documented that phytochemicals especially flavonoid-like polyphenols negatively impact insect molting by interfering with prothoracicotropic hormone and ecdysteroid action resulting to delayed maturity and abnormal developmental phenotypes or mortality [61]. Growth and development transitions in immature insects are orchestrated by morphological and ultra-structural changes regulated by coordinated actions of $\mathrm{JH}$, ecdysone and eclosion hormones [62]. Insulin/insulin-like signaling interplay between the developmental events to ensure static allometry in holometabolous insects [63-65]. Hence, any exogenous agent that interferes with either the signaling networks or homeostasis of the insect developmental hormones might result in abnormal growth and development as observed in Fig. 3.

Plant-based IGRs with similar effects on developing mosquitoes have been previously reported to effectively suppress mosquito populations [66-71]. C. sinensis is favoured over other plants as a potential source of mosquito control agents because it is (i) cultivatable (ii) non-endangered plant species, and (iii) its waste can be recycled. Our findings suggest that green tea leaf proanthocyanidins could be employed to control malaria vector populations. It is paramount to conduct studies to determine toxicity effects of proanthocyanidins against non-target organisms prior to commercialization and large scale field application of this product as larvicidal agent. Further, studies encompassing molecular target identification, simulation and ligand docking are recommended to create avenues for synthesizing structurally similar candidate analogs to ease application.

\section{Conclusion}

In Kenya, C. sinensis is grown as a major cash crop. We found that the leaf extract and its active constituents have great potential for controlling mosquito larvae. Proanthocyanidins were the abundant compounds tightly associated with toxicity of larvae though the other compounds identified in the extract may contribute to bioactivity. Besides causing larval toxicity, the sublethal doses induced growth disruption effects that inhibited adult emergence.

\section{Abbreviations}

LLINs: Long-lasting insecticide treated nets; IRS: Indoor residual spraying; IVM: Integrated vector management; PMD: p-Menthane-3,8-diol; WHO: World Health Organization; IGRs: Insect growth regulators

\section{Acknowledgements}

The authors wish to thank icipe's Milcah Gitau and Richard Ochieng' for their technical assistance. We appreciate Mr. Peter Kihara and Kariuki of Limuru Archdiocesan Farm for their assistance during collection of plant samples.

\section{Funding}

Not applicable.

\section{Availability of data and materials}

The datasets supporting the conclusion of this article are included within the article.

Authors' contributions

$J_{M M}^{*}$, JLB, SGN, JMM, SNN conceived and designed experiments. JMM* performed experiments. JMM*, JLB contributed reagents/materials/analysis tools. JMM* ${ }^{*}, J \mathrm{~B}, \mathrm{SNN}$ analyzed data. $\mathrm{JMM}^{*}$ wrote the first manuscript draft. All authors read and approved the final version.

Competing interests

The authors declare that they have no competing interests.

Consent for publication

Not applicable. 


\section{Ethics approval and consent to participate}

Not applicable.

\begin{abstract}
Author details
'Department of Biochemistry, Jomo Kenyatta University of Agriculture and Technology, P.O. Box 62000-00200, Nairobi, Kenya. ${ }^{2}$ Molecular Biology and Bioinformatics Unit, International Centre of Insect Physiology and Ecology, P.O. Box 30772-00100, Nairobi, Kenya. ${ }^{3}$ Malaria Research Programme, International Centre of Insect Physiology and Ecology, P.O. Box 30772-00100, Nairobi, Kenya. ${ }^{4}$ Present Address: Fritz Lipmann Institute (FLI) - Leibniz Institute for Age Research, D-07745 Jena, Germany.
\end{abstract}

Received: 18 July 2016 Accepted: 2 September 2016 Published online: 22 September 2016

\section{References}

1. WHO. World Malaria Report 2015. World Heal. Organ. 2015; pp. 1-280.

2. Gimnig JE, Ombok M, Kamau L, Hawley WA. Characteristics of larval anopheline (Diptera: Culicidae) habitats in Western Kenya. J Med Entomol. 2001:38.

3. Matthews $\mathrm{G}$. Integrated vector management: controlling vectors of malaria and other insect vector borne diseases. Oxford: John Wiley \& Sons; 2011.

4. Chaki PP, Kannady K, Mtasiwa D, Tanner M, Mshinda H, Kelly AH, et al. Institutional evolution of a community-based programme for malaria control through larval source management in Dar es Salaam, United Republic of Tanzania. Malar J. 2014:13:1-13.

5. Fillinger U, Ndenga B, Githeko A, Lindsay SW. Integrated malaria vector control with microbial larvicides and insecticide-treated nets in western Kenya: a controlled trial. Bull World Health Organ SciELO Public Health. 2009:87:655-65.

6. David J-P, Ismail HM, Chandor-Proust A, Paine MJI. Role of cytochrome P450s in insecticide resistance: impact on the control of mosquito-borne diseases and use of insecticides on Earth. Philos Trans R Soc B Biol Sci. 2013;368:20120429.

7. Nkya TE, Akhouayri I, Kisinza W, David J-P. Impact of environment on mosquito response to pyrethroid insecticides: facts, evidences and prospects. Insect Biochem Mol Biol. 2013:43:407-16.

8. Russell TL, Beebe NW, Cooper RD, Lobo NF, Burkot TR. Successful malaria elimination strategies require interventions that target changing vector behaviours. Malar J. 2013;12:1-5.

9. Ranson H, Lissenden N. Insecticide resistance in African Anopheles mosquitoes: a worsening situation that needs urgent action to maintain malaria control. Trends Parasitol. 2016;32:187-96.

10. Khater HF. Ecosmart biorational insecticides: alternative insect control strategies. In: Perveen F, editor. Insectic Adv Integr Pest Manag. Rijeka, Croatia: InTech; 2012. ISBN 979-953-307-667-5.

11. Isman MB, Akhtar Y. Plant natural products as a source for developing environmentally acceptable insecticides. Insectic. Des. using Adv. Technol. Heidelberg: Springer; 2007. p. 235-48.

12. Mordue (Luntz) AJ, Morgan ED, Nisbet AJ. Azadirachtin, a natural product in insect control. Compr. Mol. Insect Sci. Amsterdam: Elsevier; 2005. p. 117-35.

13. Imbahale SS, Mukabana WR. Efficacy of neem chippings for mosquito larval control under field conditions. BMC Ecol. 2015;15:1.

14. Carroll SP, Loye J. PMD, a registered botanical mosquito repellent with deet-like efficacy. J Am Mosq Control Assoc. 2006;22:507-14.

15. Bernays EA, Cooper-Driver GA, Bilgener M. Herbivores and plant tannins. Adv Ecol Res. 1989;19:263-302.

16. Dixon RA, Xie D-Y, Sharma SB. Proanthocyanidins - a final frontier in flavonoid research? New Phytol. 2005;165:9-28,

17. Beecher GR. Proanthocyanidins: biological activities associated with human health. Pharm Biol. 2004:42:2-20.

18. Molan AL, Faraj AM. The effects of condensed tannins extracted from different plant species on egg hatching and larval development of Teladorsagia circumcincta (Nematoda: Trichostrongylidae). Folia Parasitol. 2010;57:62-8.

19. Barbehenn RV, Peter CC. Tannins in plant-herbivore interactions. Phytochemistry. 2011;72:1551-65.

20. Moller-Jacobs LL, Murdock CC, Thomas MB. Capacity of mosquitoes to transmit malaria depends on larval environment. Parasit Vectors. 2014;7:1-12.

21. Bara J, Rapti Z, Caceres CE, Muturi EJ. Effect of larval competition on extrinsic incubation period and vectorial capacity of Aedes albopictus for dengue virus. PLoS One. 2015;10:e0126703.
22. Ndenga BA, Simbauni JA, Mbugi JP, Githeko AK. Physical, chemical and biological characteristics in habitats of high and low presence of anopheline larvae in Western Kenya Highlands. PLoS One. 2012;7:e47975.

23. Fillinger U, Lindsay SW. Suppression of exposure to malaria vectors by an order of magnitude using microbial larvicides in rural Kenya. Trop Med Int Heal. 2006;11:1629-42.

24. Mwangangi JM, Mbogo CM, Muturi EJ, Nzovu JG, Kabiru EW, Githure Jl, et al. Influence of biological and physicochemical characteristics of larval habitats on the body size of Anopheles gambiae mosquitoes (Diptera: Culicidae) along the Kenyan coast. J Vector Borne Dis. 2007;44:122-7.

25. Breaux JA, Schumacher MK, Juliano SA. What does not kill them makes them stronger: larval environment and infectious dose alter mosquito potential to transmit filarial worms. Proc R Soc London B Biol Sci. 2014;281.

26. Killeen GF, Fillinger U, Kiche I, Gouagna LC, Knols BGJ. Eradication of Anopheles gambiae from Brazil: lessons for malaria control in Africa? Lancet Infect Dis. 2002;2:618-27.

27. Walker K, Lynch M. Contributions of Anopheles larval control to malaria suppression in tropical Africa: review of achievements and potential. Med Vet Entomol. 2007;21:2-21.

28. Chacko SM, Thambi PT, Kuttan R, Nishigaki I. Beneficial effects of green tea: a literature review. Chin Med. 2010:5:1-9.

29. Žabar A, Cvetković V, Rajković J, Jović J, Vasiljević P, Mitrović T. Larvicidal activity and in vitro effects of green tea (Camellia sinensis L.) water infusion. Biol Nyssana. 2013;4

30. Ranaweera SS. Mosquito-lavicidal activity of some Sri Lankan plants. J Natl Sci Found Sri Lanka. 1996;24.

31. Lopez TE, Pham HM, Barbour J, Tran P, Van Nguyen B, Hogan SP, et al. The impact of green tea polyphenols on development and reproduction in Drosophila melanogaster. J Funct Foods. 2015;20:556-66.

32. WHO. Guidelines for laboratory and field testing of mosquito larvicides. Geneva: World Health Organization; 2005. p. 1-41.

33. Tavares L, McDougall GJ, Fortalezas S, Stewart D, Ferreira RB, Santos CN. The neuroprotective potential of phenolic-enriched fractions from four Juniperus species found in Portugal. Food Chem. 2012;135:562-70.

34. Lambert M, Meudec E, Verbaere A, Mazerolles G, Wirth J, Masson G, et al. A high-throughput UHPLC-QqQ-MS method for polyphenol profiling in rosé wines. Molecules. 2015;20:7890-914.

35. Tusting LS, Thwing J, Sinclair D, Fillinger U, Gimnig J, Bonner KE, et al. Mosquito larval source management for controlling malaria. Cochrane Database Syst Rev. 2013;8:CD008923.

36. Maheu-Giroux M, Castro MC. Cost-effectiveness of larviciding for urban malaria control in Tanzania. Malar J. 2014;13:1-12.

37. Matthews G. Pesticides: health, safety and the environment. Oxford: John Wiley \& Sons; 2015.

38. Ghosh A, Chowdhury N, Chandra G. Plant extracts as potential mosquito larvicides. Indian J Med Res. 2012;135:581-98.

39. Nyamoita MG. Toxicity of individual and blends of pure phytoecdysteroids isolated from Vitex schiliebenii and Vitex payos against Anopheles gambiae SS larvae. World J Org Chem. 2013;1:1-5.

40. Mithöfer A, Boland W. Plant defense against herbivores: chemical aspects. Annu Rev Plant Biol. 2012;63:431-50.

41. Lee S-H, Oh H-W, Fang Y, An S-B, Park D-S, Song H-H, et al. Identification of plant compounds that disrupt the insect juvenile hormone receptor complex. Proc Natl Acad Sci. 2015;112:1733-8.

42. Laranja AT, Manzatto AJ, Campos Bicudo HEM de. Effects of caffeine and used coffee grounds on biological features of Aedes aegypti (Diptera, Culicidae) and their possible use in alternative control. Genet Mol Biol. 2003;26(4):419-29.

43. Aligiannis N, Mitaku S, Mitrocotsa D, Leclerc S. Flavonoids as cycline-dependent kinase inhibitors: inhibition of cdc 25 phosphatase activity by flavonoids belonging to the quercetin and kaempferol series. Planta Med. 2001;67:468-70

44. War AR, Paulraj MG, Ahmad T, Buhroo AA, Hussain B, Ignacimuthu S, et al. Mechanisms of plant defense against insect herbivores. Plant Signal Behav. 2012;7:1306-20

45. Procópio TF, Fernandes KM, Pontual EV, Ximenes RM, de Oliveira ARC, Souza CDS, et al. Schinus terebinthifolius leaf extract causes midgut damage, interfering with survival and development of Aedes aegypti larvae. PLoS One. 2015;10:e0126612.

46. Gupta S, Ahmad N, Nieminen A-L, Mukhtar H. Growth inhibition, cell-cycle dysregulation, and induction of apoptosis by green tea constituent (-)-epigallocatechin-3-gallate in androgen-sensitive and androgen-insensitive human prostate carcinoma cells. Toxicol Appl Pharmacol. 2000;164:82-90. 
47. Khan N, Afaq F, Saleem M, Ahmad N, Mukhtar H. Targeting multiple signaling pathways by green tea polyphenol (-)-epigallocatechin-3-gallate. Cancer Res. 2006;66:2500-5.

48. Lee LA, Orr-Weaver TL. Regulation of cell cycles in Drosophila development: intrinsic and extrinsic cues. Annu Rev Genet. 2003;37:545-78.

49. Frazier RA, Deaville ER, Green RJ, Stringano E, Willoughby I, Plant J, et al. Interactions of tea tannins and condensed tannins with proteins. J Pharm Biomed Anal. 2010;51:490-5.

50. Timmel MA, Byl JAW, Osheroff N. Epimerization of green tea catechins during brewing does not affect the ability to poison human type II topoisomerases. Chem Res Toxicol. 2013;26:622-8.

51. Kuzuhara T, Sei Y, Yamaguchi K, Suganuma M, Fujiki H. DNA and RNA as new binding targets of green tea catechins. J Biol Chem. 2006;281:17446-56.

52. Tunaz $\mathrm{H}$, Uygun N. Insect growth regulators for insect pest control. Turkish J Agric For. 2004;28:377-87.

53. Staal GB. Insect growth regulators with juvenile hormone activity. Annu Rev Entomol. 1975;20:417-60

54. Dhadialla TS, Carlson GR, Le DP. New Insecticides with ecdysteroidal and juvenile hormone activity. Annu Rev Entomol. 1998;43:545-69.

55. Miyamoto J, Hirano M, Takimoto $Y$, Hatakoshi M. Insect growth regulators for pest control, with emphasis on juvenile hormone analogs. Present status and future prospects. In: Duke S, Menn J, Plimmer J, Editors. Pest control with enhanced environmental safety. ACS Symp Ser Am Chem Soc. Washington, DC; 1993;524:144-68.

56. Dinan L. Phytoecdysteroids: biological aspects. Phytochemistry. 2001;57:325-39.

57. Mitchell MJ, Keogh DP, Crooks JR, Smith SL. Effects of plant flavonoids and other allelochemicals on insect cytochrome P-450 dependent steroid hydroxylase activity. Insect Biochem Mol Biol. 1993;23:65-71.

58. Riehle MA, Brown MR. Insulin stimulates ecdysteroid production through a conserved signaling cascade in the mosquito Aedes aegypti. Insect Biochem Mol Biol. 1999;29:855-60.

59. Edgar BA. How flies get their size: genetics meets physiology. Nat Rev Genet. 2006:7:907-16.

60. Pérez-Hedo M, Rivera-Perez C, Noriega FG. The insulin/TOR signal transduction pathway is involved in the nutritional regulation of juvenile hormone synthesis in Aedes aegypti. Insect Biochem Mol Biol. 2013;43:495-500.

61. Jadhav DR, Mallikarjuna N, Rathore A, Pokle D. Effect of some flavonoids on survival and development of Helicoverpa armigera (Hübner) and Spodoptera litura (Fab) (Lepidoptera: Noctuidae). Asian J Agric Sci. 2012;4:298-307.

62. Rewitz KF, Yamanaka N, O'Connor MB. Developmental checkpoints and feedback circuits time insect maturation. Curr Top Dev Biol. 2013;103:1.

63. Shingleton AW, Frankino WA, Flatt T, Nijhout HF, Emlen DJ. Size and shape: the developmental regulation of static allometry in insects. Bioessays. 2007;29:536-48

64. Shingleton AW, Mirth CK, Bates PW. Developmental model of static allometry in holometabolous insects. Proc Biol Sci. 2008;275:1875-85.

65. Nijhout HF, Riddiford LM, Mirth C, Shingleton AW, Suzuki Y, Callier V. The developmental control of size in insects. Rev Dev Biol. 2014;3:113-34.

66. Innocent $\mathrm{E}$, Nkunya $\mathrm{MHH}$, Hassanali A. Larvicidal activity of Kotschya uguenensis plant powders and methanol extracts against Anopheles gambiae ss larvae in the laboratory and in simulated ponds. J Appl Pharm Sci. 2013;3:122

67. Owino J, Hassanali A, Ndung'u M. Bio-assay guided fractionation of anti-mosquito limonoids from Turraea abyssinica and Turraea cornucopia. J Biofertilizers Biopestic. 2014;5:1.

68. Kihampa C, Joseph CC, Nkunya MHH, Magesa SM, Hassanali A, Heydenreich $M$, et al. Larvicidal and IGR activity of extract of Tanzanian plants against malaria vector mosquitoes. J Vector Borne Dis. 2009:46:142-52.

69. Nathan SS, Kalaivani K, Murugan K. Effects of neem limonoids on the malaria vector Anopheles stephensi Liston (Diptera: Culicidae). Acta Trop. 2005;96:47-55

70. Nathan SS, Savitha G, George DK, Narmadha A, Suganya L, Chung PG Efficacy of Melia azedarach L. extract on the malarial vector Anopheles stephensi Liston (Diptera: Culicidae). Bioresour. Technol. 2006;97:1316-23.

71. Ndung'u M, Torto B, Knols BGJ, Hassanali A. Laboratory evaluation of some eastern African Meliaceae as sources of larvicidal botanicals for Anopheles gambiae. Int J Trop Insect Sci. 2004;24:311-8.

\section{Submit your next manuscript to BioMed Central and we will help you at every step:}

- We accept pre-submission inquiries

- Our selector tool helps you to find the most relevant journal

- We provide round the clock customer support

- Convenient online submission

- Thorough peer review

- Inclusion in PubMed and all major indexing services

- Maximum visibility for your research

Submit your manuscript at www.biomedcentral.com/submit
Biomed Central 